\title{
Effects of the level and duration of feeding restriction on carcass components of broilers
}

\author{
H. Jahanpour ${ }^{1}$, A. Seidavi ${ }^{2}$, A. A. A. Qotbi ${ }^{2}$, R. Van Den Hoven ${ }^{3}$, S. Rocha e Silva ${ }^{4}$, V. Laudadio ${ }^{5}$, and \\ V. Tufarelli ${ }^{5}$ \\ ${ }^{1}$ Young Researchers and Elites Club, Rasht Branch, Islamic Azad University, Rasht, Iran \\ ${ }^{2}$ Department of Animal Science, Rasht Branch, Islamic Azad University, Rasht, Iran \\ ${ }^{3}$ Institute of Animal Nutrition, Veterinary University of Vienna, Veterinärplatz 1A-1210, Vienna, Austria \\ ${ }^{4}$ CECAV, Centro de Ciência Animal e Veterinária, Universidade de Trás-os-Montes e Alto Douro, \\ Quinta de Prados, 5000-801 Vila Real, Portugal \\ ${ }^{5}$ Department of Emergency and Organ Transplantation, Section of Veterinary Science and Animal Production, \\ University of Bari “Aldo Moro", 70010 Valenzano, Bari, Italy \\ Correspondence to: V. Tufarelli (vincenzo.tufarelli@uniba.it)
}

Received: 6 January 2015 - Revised: 26 February 2015 - Accepted: 5 March 2015 - Published: 17 March 2015

\begin{abstract}
The effects of the restriction of the advised daily feed intake (ADFI) during 1 or 2 weeks on broiler body weight (BW) and carcass composition were studied. A total of 150 1-day-old male broilers (Ross-308) were randomly allotted to a control and four experimental treatments with three replicates per treatment. Broilers were subjected to a feeding restriction equal to 75 and $50 \%$ of ADFI, either for a 7- or a 14-day period, between the 7th and 14th and 7th and 21th day of age, respectively. The BW and carcass composition were determined on day 42. From the findings, neither of the two levels of restriction nor the two time intervals had significant effects $(P>0.05)$ on the BW or breast and leg weight and proportion, liver and most of the body components. However, the feeding treatments show a tendency $(P=0.078)$ to influence the BW, with birds fed $75 \%$ of ADFI for 14 day being heavier than the control group. For eviscerated carcass weight, an effect $(P=0.002)$ was observed, with birds fed $75 \%$ of ADFI for 14 day having heavier carcasses $(P<0.05)$ than those in control group. The abdominal fat, both with regard to weight and proportion, was slightly influenced by dietary treatments $(P>0.05)$. From our results, it can be concluded that the applied feeding restrictions have a neutral or slightly beneficial effect on broiler growth traits and carcass composition.
\end{abstract}

\section{Introduction}

Specific selection for high growth rate in broilers by the poultry industry has resulted in branded strains that reach a high end weight within a short rearing period (Boyle, 2005). Selection effects are displayed in carcass composition and structure, growth pattern, metabolism, digestion, endocrine and immune functions, central nervous system functions, and even in the behaviour of broilers (Khajavi et al., 2003; Dawkins and Layton, 2012). Cardiovascular disorders, skeletal disease and higher susceptibility to other metabolic diseases are commonly reported in commercial broilers. In fact, sudden death syndrome (Govaerts et al., 2000) and ascites (Kalmar et al., 2013; Wideman et al., 2013) are well- known problems in these broilers, in addition to low immunity and disease resistance (Robinson et al., 1992). Moreover, increased pressure on legs and hips leads to limb abnormalities, which reduces the ability to move (Caplen et al., 2012). Ultimately, mortality and welfare are also associated with broiler rapid growth (Leeson and Summers, 2001; Dawkins and Layton, 2012).

The rapid growth and propensity to fatness of selected broilers result from their high appetite. If feed is offered ad libitum, these broilers will consume more than 2 to 3 times their maintenance requirements (Barbato, 1994); part of the dietary energy is not utilized for the production of edible por- 
tions of meat but is wasted as abdominal fat (Mushtaq et al., 2014).

Almost all the progress in improved food conversion attained by selection is due to a reduction in maintenance requirements (Teimouri et al., 2005). The selection for a high growth rate is marked by increased carcass fat, increased carcass water content and increased breast muscles (Havenstein et al., 2003). In order to improve the feed efficiency and reduce fat deposition, planned feed restriction has been adopted in broiler production (Jones and Farrel, 1992; Eila et al., 2011; Mirshamsollahi, 2013). Some reports showed that early-age feed-restricted broilers did compensate for initial retarded growth and reduce carcass fat (Plavnik and Hurwitz, 1985; Leeson and Zubair, 1997; Molapo and Webb, 2014). Santoso (2001) fed broilers with 25,55 and $75 \%$ of the usual ration; when compared to a control group, those birds did compensate for initial retarded growth. The feed-restricted broilers had lower levels of triglycerides and abdominal fat at the finishing age. A similar effect of food restriction on carcass fat was also reported by Leeson and Zubair (1997), who fed only $50 \%$ of the normal feed quantity during the 6th to the 11th day of rearing and showed that this level of restriction reduced carcass fat and abdominal fat. This corroborates other studies that also show that most fat storage develops in the first stage of the rearing period (Yu and Robinson, 1992) and that feed restriction at early postnatal stage produces long-term effects on lipid metabolism (Yang et al., 2010). Although researchers agree that feed-restriction programs reduce abdominal and carcass fat, the effect of early feed restriction on other carcass and body components is diverse. In fact, there are some reports that show an effect of feed restriction with regard to reducing carcass and body weights at slaughter (Leeson and Summers, 2001), whereas others show no effect or even show an increase in those traits (Elia et al., 2012; Mirshamsollah, 2013). Therefore, the aim of this study was to evaluate the effects of two levels of feed restriction during different time intervals of the rearing period on broiler body weight and carcass traits.

\section{Methods}

\subsection{Housing and management}

This experiment was performed at the Faculty of Agriculture, Islamic Azad University, Rasht Branch, Iran, during the winter season. The facility was an open-sided house with six ventilators with a joined capacity of $4900 \mathrm{~m}^{3}$ per hour. The facility contained a working room, a slaughter room and a separate carcass and meat processing room. A heater was used and the temperature was regulated according to the instructions for Ross-308 (Aviagen, Newbridge, Scotland) broilers. Air relative humidity was kept at 55 to $65 \%$ during the early growing period by spraying the floor with water. Light was provided by 43 Watt lamps. The lamps were installed at a height of $2.2 \mathrm{~m}$ above the floor. Twenty-three-hour lighting was on daily, and, for 1 hour between 19:00 and 20:00, the facility was left dark. These procedures were followed until the broilers' slaughter age at day 42 . Prior to the experiment the facility was carefully cleaned, including drinkers and feeders; then the facility was disinfected. All equipment used during the rearing period, including buckets, sandals, cardboard rolls, temperature gauges, and all drinkers and feeders, were placed in the facilty, which was then fumigated. Ventilation was turned on to optimize the air $24 \mathrm{~h}$ before the broilers were brought in. The sanitation principles and health measures for raising chickens were applied. Birds were vaccinated against common diseases. After each vaccination, $1: 1000$ multivitamin + electrolytes solution was mixed in the drinking water for $24 \mathrm{~h}$. In addition to litter management, anticoccidiosis treatment with salinomycin $\left(0.5 \mathrm{~kg} \mathrm{t}^{-1}\right)$ was mixed in the diets from day 21 onwards. Feed remaining in feeders was weighed at the end of the week.

\subsection{Experimental design and diets}

A total of 150 1-day-old male chicks of the Ross-308 strain (Zarbal SP, Tehran, Iran) were allotted to 15 groups of 10 birds. The mean group body weights were similar for each group. The experimental design included a control and four treatment groups each represented by three replicates. Environmental conditions were similar for all treatments. The treatments regarding the feed levels were

- control group: feeding according to the advised daily feed intake (ADFI) in the Ross-308 instruction manual (Aviagen, Newbridge, Scotland, UK);

- treatment 1 (T1): $50 \%$ ADFI from day 8 till day 14;

- treatment 2 (T2): $50 \%$ ADFI from day 8 till day 21;

- treatment 3 (T3): $75 \%$ ADFI from day 8 till day 14;

- treatment 4 (T4): $75 \%$ ADFI from day 8 till day 21.

All chickens were fed before and after the completion of the restriction period according to the producer's feeding instructions. The ingredients of the diets and their nutrient composition in the different rearing periods are reported in Tables 1 and 2 , respectively.

\subsection{Slaughter and measurements}

At day 42 after $7 \mathrm{~h}$ of fasting for complete gut evacuation, one bird from each replicate was selected. Care was taken to choose the most representative bird according to the group mean BW (body weight). Birds were killed and were fully plucked using the dry-plucking method. At dissection, the feet were separated at the tibia-tarsal joint. The head, neck and wingtips were removed from the body; then the metabolic and digestive organs, the so-called organ fraction, were removed. The remaining body was defined as 
Table 1. Ingredient composition of diets fed to broilers during the experimental period.

\begin{tabular}{|c|c|c|c|}
\hline Ingredient $\left(\mathrm{g} \mathrm{kg}^{-1}\right)$ & Starter & Grower & Finisher \\
\hline Corn & 460.9 & 500.9 & 488.8 \\
\hline Soybean meal & 397.7 & 358.2 & 399.7 \\
\hline Fish meal & 30.0 & 30.0 & - \\
\hline Meat meal & 30.0 & 30.0 & - \\
\hline Vegetable oil & 45.6 & 54.5 & 74.7 \\
\hline DL-Methionine & 2.9 & 2.3 & 1.7 \\
\hline L-Threonine & 3.0 & - & - \\
\hline $\mathrm{Ca} \% 22 \mathrm{P} \% 18$ & 9.9 & 7.5 & 16.4 \\
\hline $\mathrm{CaCO}_{3}$ & 9.8 & 7.6 & 10.0 \\
\hline $\mathrm{NaHCO}_{3}$ & 0.5 & 0.3 & - \\
\hline $\mathrm{NaCl}$ & 3.7 & 3.7 & 3.7 \\
\hline Vitamin $^{1}$-Mineral Mixture ${ }^{2}$ & 6.0 & 5.0 & 5.0 \\
\hline
\end{tabular}

${ }^{1}$ The vitamin mixture supplied (per kilogram of feed): retinyl acetate, $2.7 \mathrm{mg}$; cholecalciferol, $42.5 \mathrm{mg}$; dl-alpha-tocopheryl acetate, $10 \mathrm{mg}$; menadione sodium bisulfite, $2 \mathrm{mg}$; riboflavin, $5 \mathrm{mg}$; Ca-pantothenate, $10 \mathrm{mg}$; niacin, $20 \mathrm{mg}$; cyanocobalamin, $0.01 \mathrm{mg}$; folacin, $0.5 \mathrm{mg}$; pyridoxine, $1.5 \mathrm{mg}$; biotin, $0.1 \mathrm{mg}$; choline chloride, $200 \mathrm{mg}$; ethoxyquin, $125 \mathrm{mg}$; bacitracin, $10 \mathrm{mg}$.

2 The mineral mixture supplied per kilogram of feed: manganese, $80 \mathrm{mg}$; zinc,

$75 \mathrm{mg}$; iron, $20 \mathrm{mg}$; copper, $5 \mathrm{mg}$; iodine, $1.2 \mathrm{mg}$; cobalt, $0.2 \mathrm{mg}$; selenium,

$0.3 \mathrm{mg}$; sodium chloride, $2500 \mathrm{mg}$; sodium sulfate, $1000 \mathrm{mg}$.

the carcass fraction. The organ fraction consisted of esophagus, trachea, gizzard, crop, pancreas, heart, liver, kidneys, lungs, spleen, thymus, bursa of Fabricius, abdominal fat, testicles, duodenum, ileum, jejunum, colon, left and right cecum, and proventriculus. The brain was removed the head. All abdominal fat, including that around the rectum, gizzard and proventriculus was collected. All components from the organ fraction were separately weighed. Moreover, the length and width of duodenum, jejunum, ileum and colon were recorded. The carcass fraction was dissected into breast, wings, legs and vertebral column with the remaining part of the neck. The breast includes the skin and sternum. Legs comprise thighs and drum sticks. Components from both the organ fraction and carcass fraction were divided according to their economic value: economically relevant parts (breast, legs and wings); less important parts (abdominal fat, liver, gizzard, heart and neck) and parts of no value (brain, head, lung, testicles and kidneys). The cranial gut segments (crop, proventriculus, pancreas and duodenum) and middle and distal gut segments (jejunum, ileum, colon and cecum) were also considered. The organs related to immune response (spleen, thymus and bursa Fabricius) were also collected and weighed. The total weight of the dissected parts and the weight of various segments of the digestive tract were compared to the eviscerated carcass weight. Ratios were calculated according to the following formula:

Relative weight of component $\%=$

$\frac{\text { Weight of component }}{\text { Weight of carcass }} \times 100$.
Table 2. Nutrient composition of diets fed to broilers.

\begin{tabular}{lrrr}
\hline Nutrients $\left(\mathrm{g} \mathrm{kg}^{-1}\right)$ & Starter & Grower & Finisher \\
\hline ME $\left(\mathrm{kcal} \mathrm{kg}^{-1}\right)$ & 3200 & 3200 & 3200 \\
Crude protein & 230.0 & 200.0 & 200.0 \\
Lysine & 14.1 & 12.6 & 12.2 \\
Methionine & 6.7 & 5.9 & 5.0 \\
Met+Cys & 10.5 & 9.4 & 8.5 \\
Threonine & 19.8 & 8.7 & 8.5 \\
Tryptophan & 3.0 & 2.7 & 2.8 \\
Arginine & 16.8 & 15.4 & 15.1 \\
Iso-Leucine & 10.4 & 9.5 & 9.4 \\
Valine & 16.0 & 10.7 & 10.3 \\
Leucine & 19.9 & 18.7 & 18.2 \\
Calcium & 10.5 & 9.0 & 8.5 \\
Available P & 5.0 & 4.5 & 4.2 \\
Sodium & 2.3 & 2.3 & 2.0 \\
Potassium & 10.0 & 9.0 & 9.3 \\
Chloride & 3.0 & 3.0 & 3.0 \\
Choline & 1.48 & 1.37 & 1.37 \\
Linoleic acid & 12.1 & 12.7 & 12.4 \\
Ether extract & 68.4 & 78.7 & 92.2 \\
Crude fiber & 37.8 & 35.2 & 37.3 \\
\hline
\end{tabular}

\subsection{Statistical analysis}

Data were analysed using the general linear model (GLM) of SAS (2004). The fixed effects included in the model were treatment group, restriction days and restriction levels. For a comparison of the group means, Duncan's multiple range test was used.

\section{Results}

The results of feeding treatments on final BW, eviscerated carcass weight and edible carcass cuts (breast, legs and wings) are presented in Table 3. The feeding treatments showed a tendency $(P=0.078)$ to influence the BW of birds in the T4 group, which showed the highest value ( $2790 \mathrm{vs.}$ $2553 \mathrm{~g}$ in the control group). For eviscerated carcass weight, a significant effect was observed $(P=0.002)$ in the control group, which performed the worst and had on average $250 \mathrm{~g}$ less compared to the T4 group. In order to ascertain whether birds from the $\mathrm{T} 4$ group performed best from an economical point of view, the yield of the valuable edible carcass cuts was considered. No statistical difference between all the group means was found. Thus, the better carcass development could not be ascribed to the development of specific body parts.

With regard to the absolute and proportional values of economically less important body and carcass components (abdominal fat, liver, gizzard, heart, neck, brain, head, lungs, testicles and kidneys) no significant differences $(P>0.05)$ were observed between treatments. Although there were no statistical differences, birds on T2 appear to have a larger amount 
Table 3. Means ( \pm SEM) of body weight, eviscerated carcass as well as the proportion of the broiler's weight that these components make up.

\begin{tabular}{|c|c|c|c|c|c|c|}
\hline \multirow[t]{2}{*}{ Item } & \multicolumn{5}{|c|}{ Treatment } & \multirow[t]{2}{*}{$P$ value } \\
\hline & Control & $\mathrm{T} 1$ & $\mathrm{~T} 2$ & $\mathrm{~T} 3$ & $\mathrm{~T} 4$ & \\
\hline Final BW (g) & $2553 \pm 46.8$ & $2768 \pm 49.5$ & $2540 \pm 113.5$ & $2622 \pm 99.8$ & $2790 \pm 32.1$ & 0.078 \\
\hline Eviscerated carcass (g) & $1925^{\mathrm{c}} \pm 38.8$ & $2114^{\mathrm{ab}} \pm 30.8$ & $1953^{\mathrm{bc}} \pm 74.2$ & $2017^{\mathrm{abc}} \pm 60.3$ & $2175^{\mathrm{a}} \pm 38.7$ & 0.002 \\
\hline Breast (g) & $645 \pm 36.0$ & $661 \pm 16.0$ & $707 \pm 75.6$ & $753 \pm 8.2$ & $756 \pm 6.3$ & 0.111 \\
\hline Legs (g) & $672 \pm 9.3$ & $703 \pm 10.6$ & $656 \pm 27.3$ & $705 \pm 14.9$ & $527 \pm 19.5$ & 0.096 \\
\hline Wings (g) & $131 \pm 7.4$ & $148 \pm 7.4$ & $149 \pm 6.9$ & $151 \pm 15.3$ & \pm 9.5 & 0.084 \\
\hline \multicolumn{7}{|l|}{ Proportion $(\%)^{*}$} \\
\hline Breast & $34.2 \pm 1.3$ & $35.7 \pm 0.2$ & $32.8 \pm 2.6$ & $35.1 \pm 1.3$ & $34.6 \pm 0.8$ & 0.247 \\
\hline Legs & $34.9 \pm 0.2$ & $33.3 \pm 0.4$ & $33.6 \pm 0.3$ & $35.0 \pm 0.9$ & $24.7 \pm 9.2$ & 0.096 \\
\hline Wings & $6.8 \pm 0.5$ & $7.4 \pm 0.3$ & $7.6 \pm 0.6$ & $7.4 \pm 0.7$ & $6.9 \pm 0.4$ & 0.132 \\
\hline
\end{tabular}

* Valuable parts in relation to eviscerated carcass; $n=3$ per replicate; values in each row with a different lower-case superscript are significantly different $(P<0.05)$.

of abdominal fat (49 vs. 24-30 g) than the other restricted groups and $20 \%$ more than the control group. The feeding treatments had no effect $(P>0.05)$ on the cranial gut segments (crop, proventriculus, pancreas and duodenum) or on the middle and distal gut segments. Birds in T4, T1 and control groups had the highest duodenum weight, followed by T2 and T3 having the lowest duodenum weight. With regard to the colon proportion, differences $(P<0.05)$ were observed between the control and the T3 group, with 3.5 and $2.8 \%$, respectively. Treatments were observed to have a significant effect on duodenum length $(P=0.003)$; in particular, broilers in the control group had the longest duodenum (32 vs. 27$28 \mathrm{~cm}$ in the other feeding treatments). Colon width was significantly $(P=0.001)$ different between treatments; in fact, birds in the control, T1 and T2 groups showed a wider colon compared to the $\mathrm{T} 3$ and $\mathrm{T} 4$ groups. With regard to the absolute and relative weight of the spleen and thymus of broilers, no treatment effect was recorded among feeding groups; however, an effect was recorded for the bursa of Fabricius (Table 4).

\section{Discussion}

Profitable broiler production mainly depends on controlling the costs of rearing and management and on the prices of edible meat cuts. The whole carcass and parts such as breast and legs are the most valuable edible cuts. Although fat is one of the parameters influencing meat taste, it is commonly defined as a less desired trait. Thus, a profitable broiler prior to slaughter should be well muscled and not too fat. Moreover, heads, wings and less valuable parts should be as small as is biologically possible. In this study, we analysed body weight, eviscerated carcass weight and the proportion of carcass cuts and various body components of broilers kept under different early-age restricted feeding regimes in order to identify which was potentially more adequate to use under field conditions. There are some reports of the effects of feed restriction on the performance, immunity and blood parameters of broilers (Jahanpour et al., 2012, 2013, 2014). It was observed that during the period of restricted feeding, as expected, the growth rate was less in the birds on a restricted diet than in those fed the full diet (data not shown), but the former did compensate for this when on full rations. It is generally accepted that after restriction, compensatory growth will be attained (Summers et al., 1990; Lee and Leeson, 2001). Feeding a high-energy and protein diet to previously restricted broilers results in better growth compared to birds fed in the standard way. This result was also observed in our current study. The reduced maintenance requirements induced by feed restriction cause the dietary nutrients of a normal ration to be used more efficiently (Jones, 1995). Lee and Leeson (2001) showed that with such regimes, broilers had completely compensated for their initial growth retardation at the time of slaughter and, therefore, a similar body weight was expected at the end of the growing period.

Feed restriction effects may be either neutral or beneficial for the whole carcass or carcass cut weights. Summers et al. (1990) investigated a $50 \%$ feed restriction program in 5-11-day-old broilers and did not report significant differences in carcass weight, whereas in other feed restriction studies carcass weight was increased (Tumova et al., 2002). In the present study, there was a significant effect of feed restriction on eviscerated carcass weight. Birds kept on a feeding program from day 8 till day 21 with just $75 \%$ of the ADFI had, on average, heavier carcasses than those in the control group. This result may indicate that some carcass and body components of non-restricted birds grow at the expenses of more valuable parts. Some contribution to lower carcass yield may be associated with economically less important carcass components. Carcass cuts from our results are consistent with findings reported by Mirshamsollahi (2013). 
Table 4. Mean ( \pm SEM) of weight of organs related to the immune response of broilers and the proportion of total weight that they make up.

\begin{tabular}{lrrrrrr}
\hline Trait & \multicolumn{5}{c}{ Treatment } & \multirow{2}{*}{$P$ value } \\
\cline { 2 - 5 } & Control & $\mathrm{T} 1$ & $\mathrm{~T} 2$ & $\mathrm{~T} 3$ & $\mathrm{~T} 4$ & \\
\hline Spleen $(\mathrm{g})$ & $3.6 \pm 0.9$ & $2.6 \pm 0.2$ & $3.5 \pm 0.2$ & $2.4 \pm 0.1$ & $2.8 \pm 0.1$ & 0.068 \\
Thymus (g) & $12.6 \pm 1.0$ & $13.4 \pm 4.2$ & $9.1 \pm 3.4$ & $15.4 \pm 1.1$ & $11.5 \pm 1.3$ & 0.061 \\
Bursa Fabricii (g) & $4.8^{\mathrm{ab}} \pm 0.5$ & $5.6^{\mathrm{a}} \pm 0.2$ & $3.2^{\mathrm{ab}} \pm 0.7$ & $5.1^{\mathrm{a}} \pm 1.8$ & $1.9^{\mathrm{b}} \pm 0.2$ & 0.014 \\
\hline Proportion (\%) & & & & & \\
\hline Spleen & $0.2 \pm 0.1$ & $0.1 \pm 0.1$ & $0.2 \pm 0.2$ & $0.1 \pm 0.0$ & $0.1 \pm 0.2$ & 0.574 \\
Thymus & $0.7 \pm 0.5$ & $0.6 \pm 0.2$ & $0.5 \pm 0.2$ & $0.8 \pm 0.1$ & $0.5 \pm 0.1$ & 0.076 \\
Bursa Fabricii & $0.25^{\mathrm{a}} \pm 0.1$ & $0.26^{\mathrm{a}} \pm 0.1$ & $0.17^{\mathrm{b}} \pm 0.1$ & $0.25^{\mathrm{a}} \pm 0.1$ & $0.08^{\mathrm{b}} \pm 0.2$ & 0.030 \\
\hline
\end{tabular}

Values in each row with a different lower-case superscript are significantly different $(P<0.05) . n=3$ per replicate.

In general, both the weight and proportion of carcass cuts were not significantly affected by feed restriction programs. However, Tumova et al. (2002) reported an increase in breast muscle weight after a feed restriction regime.

In broilers, the liver is the main site of lipid production, whereas fatty tissue, especially in the abdomen, is the main site for fat storage (Leenstra, 1986). Feed restriction reduces metabolic efficiency of the liver; thus, the effect of the intensity and duration of restriction may cause a reduction in liver weight (Jones, 1995). However, after the rehabilitation period, some authors reported a liver enlargement (Zubair and Leeson, 1996; Leeson and Zubair, 1997, Ozdogan and Aksit, 2003). An explanation for this is that after the cessation of restricted feeding, birds will overeat, such that the liver will enlarge. However, in the present study, this seems not to have occurred or at least did not have long-lasting effects, since none of our restriction feeding regimes caused lower liver weights at slaughter.

Feed restriction at an early age may reduce the hepatic capacity of lipid production, which subsequently results in a lower weight of abdominal fat (Jones and Farrel, 1992). The fat storage process and the development of body fat in broilers take place in a two-stage process (Jones and Farrel, 1992). At first the proliferation rate of fat cells is dominant; later, fat storage becomes more evident until the third week of life, in which fat storage rate becomes dominant. The possibility to reduce body fat weight by feed restriction thus may be explained by the decreased rate of lipocyte proliferation. However, there are conflicting reports on this issue, since some studies extrapolated the event observed in 42-day-old chicks back to a state that may have be present at an earlier age. Looking at 42-day-old broilers, Zhong et al. (1995) did not observe that feed restriction reduced the amount of abdominal fat cells. However, they reported that lipocytes had become smaller. In contrast, Zubair and Leeson (1996) showed that, at 42 days of age, lipocyte numbers decreased in the abdominal fat of restricted chicks, but the cells size was not different from that in the control. Benyi et al. (2009) examined the effects of skip-a-day feeding for 14 or 28 days during the starter and grower periods and found that feed efficiency and abdominal fat were unaffected. Our findings are in accordance with those findings, although a tendency to an increase in abdominal fat for the strongly restricted group (14 days, $50 \%$ ADFI) was observed. It appears that the duration of the restriction plays a role in this phenomenon, since only a short period of feed restriction had an effect on the amount of abdominal fat (Tottori et al., 1997). Our results are consistent with those of Plavink and Hurwitz (1985) and Jones and Farrel (1992). According to Plavink and Hurwitz (1985) the growth retardation of fat cells and the reduced rate of fat production by the smaller livers at the time of feed restriction is the reason that less fat will be accumulated in the carcass later.

The size and function of the digestive tract plays a keyrole in growth. Feed restrictions may also affect the digestive tract in its size and function and thus may limit absorption of nutrients for growth. Palo et al. (1995) reported that the absolute weight of internal organs of restricted birds is less than in those of the control group immediately after the restriction period. In contrast to this study, Zubair and Leeson (1996) found that the relative weight of the digestive system's organs during the restriction period was generally higher than in chicks fed normally. This phenomenon may be a part of a compensatory mechanism to enhance extra growth. However, in our study, the absolute and relative weights of the digestive tract at day 42 for the different treatments compared to the control were not significantly different. Therefore, it appears that the growth of the gut and body weight proceeds at equal rates.

The dimensions of digestive tract are associated with growth and therefore were also measured in this study. Our findings showed that the non-restricted birds appeared to have a longer duodenum, and broilers on $75 \%$ ADFI (both for 1 and 2 weeks) have a wider colon. In the other gut segments, no differences in length and width were observed. Little information is available on the effect of feed restriction on the length and width of gut segments; however, some authors report results on intestine length (Novele et al., 2008; Silva 
and Kalubowila, 2012). Novele et al. (2008) found that chickens on 75 and $50 \%$ ad libitum feeding had a similar intestine length at 42 days of age, whereas Silva and Kalubowila (2012) reported that restricted feeding reduced a short intestine length.

Feed restriction programs appear also to reduce mortality (Aerts et al., 2003). The level of the reduction of mortality by metabolic diseases seems to depend on the level and duration of the feed restriction program applied (Leeson and Summers, 2001). The results of feed restriction on mortality in our study ( $3 \%$ including the control group, data not shown) are consistent with those of Lippens et al. (2000) and Lee and Leeson (2001) but contrast with Teimouri et al. (2005) and Gonzales et al. (1998), who reported a higher rate $(\sim 4 \%)$. However, all these authors used only mildly restricted rations.

\section{Conclusions}

In conclusion, feeding restriction regimes in broilers with feed intake levels of 50 and $75 \%$ of the advised daily intake, applied for 1 or 2 weeks, have a neutral or beneficial effect on weight at slaughter and on carcass traits. No feeding restriction effects were observed on leg or breast; however, the valuable meat cuts show a tendency to be heavier. Thus, feeding restriction programs could be usefully applied as a management technique in rearing commercial broilers with no detrimental effects on carcass traits.

Acknowledgements. This paper is based on the MSc thesis of Hossein Jahanpour at the Islamic Azad University, Rasht Branch, Rasht, Iran. We are also grateful to the Islamic Azad University, Rasht Branch, Rasht, Iran for support.

Edited by: S. Maak

Reviewed by: three anonymous referees

\section{References}

Aerts, J. M., Van Buggenhout, S., Vranken, E., Lippens, M., Buyse, J., Decuypere, E., Berckmans, D.: Active control of the growth trajectory of broiler chickens based on on-line animal responses, Poult. Sci., 82, 1853-1862, 2003.

Barbato, G. F.: Genetic control of food intake in chickens, J. Nutr., 124, 1341S-1348S, 1994.

Benyi, K., Acheampong-Boateng, O., Norris, D., Mathoho, M., and Mikasi, M. S.: The response of Ross 308 and Hybro broiler chickens to early and late skip-a-day feed restriction, Trop. Anim. Health Prod., 41, 1701-1713, 2009.

Boyle, M.: The modern poultry yield (r)evolution, Int. Poult. Prod., 13, 7-11, 2005.

Caplen, G., Hothersall, B., Murrell, J. C., Nicol, C. J., WatermanPearson, A. E., Weeks, C. A., and Colborne, R. G.: Kinematic analysis quantifies gait abnormalities associated with lameness in broiler chickens and identifies evolutionary gait differences, PLoS One, 7, e40800, doi:10.1371/journal.pone.0040800, 2012.

Dawkins, M. S. and Layton, R.: Breeding for better welfare: genetic goals for broiler chickens and their parents, Anim. Welfare, 21, 147-155, 2012.

Eila, N., Lavvaf, A. G., and Farahvash, T.: Comparison of different feed restriction methods on growth performance of broilers, Res. Opin. Anim. Vet. Sci., 1, 686-688, 2011.

Eila, N., Lavvaf, A. G., Farahvash, T., and Zarei, A.: Influence of various growth patterns on performance of Ross 308 broilers, Pak. Vet. J., 32, 372-374, 2012.

Gonzales, E., Buyse, J., Loddi, M. M., Takita, T. S., Buys, N., and Decuypere, E.: Performance, incidence of metabolic disturbances and endocrine variables of food restricted male broiler chickens, Br. Poult. Sci., 39, 671-678, 1998.

Govaerts, T., Room, G., Buyse, J., Lippens, M., Degroote, G., and Decuypere, E.: Early and temporary quantitative food restriction of broiler chickens. 2. Effect on allometric growth and growth hormone secretion, Br. Poult. Sci., 41, 355-362, 2000.

Havenstein, G. B., Ferket, P. R., and Qureshi, M. A.: Growth, livability, and feed conversion of 1957 versus 2001 broilers when fed representative 1957 and 2001 broiler diets, Poult. Sci., 82, 1500-1508, 2003.

Jahanpour, H., Seidavi, A., and Qotbi, A. A. A.: Effects of intensity and duration of feed quantitative restriction on broiler immune system, Ann. Biol. Res., 3, 2656-2661, 2012.

Jahanpour, H., Seidavi, A., Qotbi, A. A. A., and Payan-Carreira, R.: Effects of two levels of quantitative feed restriction for a 7- or 14- days period on broilers blood parameters, Acta Sci. Vet., 41, $1144,2013$.

Jahanpour, H., Seidavi, A., and Qotbi, A. A. A.: Effects of intensity and duration of quantitative restriction of feed on broiler performance, J. Hell. Vet. Med. Soc., 65, 83-98, 2014.

Jones, G. P. D.: Manipulation of organ growth by early life food restriction: Its influence on the development of ascites in broiler chickens, Br. Poult. Sci., 36, 135-142, 1995.

Jones, G. P. D. and Farrel, D. J.: Early-Life food restriction of chicken. II. Effect of food restriction on the development of fat tissue, Br. Poult. Sci., 33, 589-601, 1992.

Kalmar, I. D., Vanrompay, D., and Janssens, G. P. J.: Broiler ascites syndrome: Collateral damage from efficient feed to meat conversion, Vet. J., 197, 169-174, 2013.

Khajavi, S., Rahimi, Z. M., Hasan, M., Kamali, A., and Mousavi, T.: Effect of feed restriction early in life on humoral and cellular immunity of two commercial broiler strains under heat stress conditions, Br. Poult. Sci., 44, 490-497, 2003.

Lee, K. H. and Leeson, S.: Performance of broilers fed limited quantities of feed or nutrients during seven to fourteen days of age, Poult. Sci., 80, 446-454, 2001.

Leenstra, F. R.: Effect of age, sex, genotype and environment on fat deposition in broiler chickens: a review, World Poult. Sci. J., 42, 12-25, 1986.

Leeson, S. and Summers, J. D.: Scott's nutrition of the chicken, 4th ed., Guelph, University Books, Canada, 2001.

Leeson, S. and Zubair, A. K.: Nutrition of the broiler chicken around the period of compensatory growth, Poult. Sci., 76, 992-999, 1997.

Lippens, M., Room, G., De Groote, G., and Decuypere, E.: Early and temporary quantitative food restriction of broiler chickens. 
Effect on performance characteristics, mortality and meat quality, Br. Poult. Sci., 41, 343-354, 2000.

Mirshamsollahi, A.: Effect of different food restriction on performance and carcass characteristics of Arian and Ross broiler chicks, Int. J. Agric. Res. Rev., 3, 495-501, 2013.

Molapo, S. M. and Webb, E. C.: Effect of restricted feeding on the carcass characteristics of Koekoek chickens, Res. Opin. Anim. Vet. Sci., 4, 299-304, 2014.

Mushtaq, M. M. H., Pasha, T. N., Mushtaq, T., Akram, M., Mahmood, S., Farooq, U., and Parvin, R.: Growth, water intake, litter moisture, carcass and physiological traits of broiler chickens fed varying levels and sources of potassium under phase feeding system, Livest. Sci., 159, 61-66, 2014.

Novele, D. J., Ng'Ambi, J. W., Norris, D., and Mbajiorgu, C. A.: Effect of sex, level and period of feed restriction during the starter stage on productivity and carcass characteristics of Ross 308 broiler chickens in South Africa, Int. J. Poult. Sci., 7, 530-537, 2008.

Ozdogan, M. and Aksit, M.: Effects of feeds containing different fats on carcass and blood parameters of broilers, J. Appl. Poult. Res., 12, 251-256, 2003.

Palo, P. E., Sell, J. L., Piquer, F. J., Soto-Salanova, M. F., and Vilaseca, L.: Effect of early nutrient restriction on broiler chickens. I. Performance and development of the gastrointestinal tract, Poult. Sci., 74, 88-101, 1995.

Plavnik, I. and Hurwitz, S.: The performance of broiler chicks during and following a severe food restriction at an early age, Poult. Sci., 64, 348-355, 1985.

Robinson, F. E., Classen, H. L., Hanson, J. A., and Onderka, D. K.: Growth performance, feed efficiency and the incidence of skeletal metabolic disease in full-fed and feed restricted broiler and roaster chickens, J. Appl. Poult. Res., 1, 33-41, 1992.

Santoso, U.: Effect of early feed restriction on growth, fat accumulation and meat composition in unsexed broiler chickens, AsianAustral. J. Anim. Sci., 4, 1585-1591, 2001.
Silva, P. H. and Kalubowila, A.: Influence of feed withdrawal for three hour time period on growth performance and carcass parameters of later stage of male broiler chickens, Iran. J. Appl. Anim. Sci., 2, 191-197, 2012.

Summers, J. D., Spratt, D., and Atkinson, J. L.: Restricted feed and compensatory growth for broiler, Poult. Sci., 69, 1855-1861, 1990.

Teimouri, A., Rezaei, M., Pourreza, M. J., Sayyahzadeh, H., and Waldroup, P. W.: Effect of diet dilution in the starter period on performance and carcass characteristics of broiler chicks, Int. J. Poult. Sci., 12, 1006-1011, 2005.

Tottori, J., Yamaguchi, R., Murakawa, Y., Sato, M., Uchida, K., and Tateyama, S.: The use of feed restriction for mortality control of chickens in broilers, Avian Dis. 42, 433-437, 1997.

Tumova, E., Skrivan, M., Skrivanova, V., and Kacerovska, L.: Effect of early feed restriction on growth in broiler chickens, turkeys and rabbits, Czech J. Anim. Sci., 47, 418-28, 2002.

Wideman, R. F., Rhoads, D. D., Erf, G. F., and Anthony, N. B.: Pulmonary arterial hypertension (ascites syndrome) in broilers: A review, Poult. Sci., 92, 64-83, 2013.

Yang, X., Zhuang, J., Rao, K., Li, X., and Zhao, R.: Effect of early feed restriction on hepatic lipid metabolism and expression of lipogenic genes in broiler chickens, Res. Vet. Sci., 89, 438-444, 2010.

Yu, M. W. and Robinson, F. E.: The application of short-term feed restriction to broiler chicken production: A review, J. Appl. Poult. Res., 1, 147-153, 1992.

Zhong, C., Nakaue, H. S., Hu, C. Y., and Mirosh, L. W.: Effect of full and early feed restriction on broiler performance, abdominal fat level, cellularity, and fat metabolism in broiler chickens, Poult. Sci., 74, 1636-1643, 1995.

Zubair, A. K. and Leeson, S.: Changes in body composition and adipocyte cellularity of male broilers subjected to varying degrees of early-life feed restriction, Poult. Sci., 75, 719-728, 1996. 